Proceedings

\title{
Identification and overcommitment in the hospital context: a comparative study in a Spanish sample of health professionals
}

\author{
${ }^{+}$Gumersindo Tirado1, Marta Llorente-Alonso', ${ }^{2}$, Cristina García-Ael ${ }^{4}$ and Gabriela Topa ${ }^{4}$ \\ 1. Department of Social, Developmental and Educational Psychology, University of Huelva, Spain; \\ gumersindo.tirado@dpsi.uhu.es \\ 2. Health Psychology Program, International School of Doctorate, National Distance Education University \\ (UNED), C/Bravo Murillo,38, 3a , 28015, Madrid; mllorente78@alumno.uned.es \\ 3. Servicio de Psiquiatría y Salud Mental, Complejo Hospitalario de Soria, Gerencia Regional de Salud de \\ Castilla y León (Sacyl), Po Santa Bárbara s/n, 42005, Soria \\ 4. National Distance Education University (UNED), Faculty of Psychology, Department of Social and Or- \\ ganizational Psychology, C/ Juan del Rosal, 10, 28040, Madrid; cgarciaael@psi.uned.es; gtopa@psi.uned.es \\ * Correspondence: gumersindo.tirado@dpsi.uhu.es; Tel.: (+34-666-26-56-60)
}

\begin{abstract}
Publisher's Note: MDPI stays neutral with regard to jurisdictional claims in published maps and institutional affiliations.
\end{abstract}

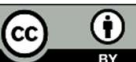

Copyright: $\odot 2021$ by the authors. Submitted for possible open access publication under the terms and conditions of the Creative Commons Attribution (CC BY) license (http://creativecommons.org/licenses/by/4.0/).

\begin{abstract}
The purpose of this study was to check whether the overcommitment, included in the Theoretical Model of Effort-Reward Imbalance (ERI), moderated the relationship between the ERI and the organizational identification in a sample of Spanish health professionals. Furthermore, we also wanted to check if this effect varied depending on the professional category (doctors vs. nurses) and age. A sample of 623 subjects participated in the study, 164 were doctors and 459 were nursing professionals. Both samples answered a set of questions related to the imbalance between effort and received rewards (ERI), the overcommitment (intrinsic component of the ERI model), and the organizational identification. The results revealed that the effect of effort-reward imbalance on organizational identification was statistically significant in professionals with medium-high overcommitment $(\beta=0.22, p<0.01 ; \beta=0.39, p<0.01)$. In the case of people with low overcommitment, this effect was not significant. These results suggest that when an imbalance between the efforts and rewards received in the organization occurred, the most overcommitment healthcare professionals identify more with the organization than those who are less committed. In addition, the relationship to age is negative and significant only for the group of nurses $(\beta=-0.012, p<0.01)$. More specifically, older nurses, were less identified with the organization. Despite the limitations, this study can contribute to a better understanding of the moderating role of overcommitment and its indirect effects on organizational identification, depending on chronological age, as well as guide possible interventions in the light of these influences.
\end{abstract}

Keywords: Effort-Reward Imbalance (ERI); Identification; Overcommitment; Health Professionals

\section{Introduction}

Although work is, in general, a source of well-being and health for people, it has repeatedly been considered a precedent of physical and mental health problems. This statement is fully consistent with the central notion of the effort-reward imbalance model (Effort-Reward Imbalance, ERI) [1, 2, 3]. This explanatory model of stress has been developed by Johannes Siegrist (1996) to identify conditions of failure of reciprocity in social commitments. The author applies the principles of social exchange and reciprocity to the field of work stress, where the expectations of employees about what their work is worth determine how they perceive their situation, so that fair exchange relations with their organization promote feelings of satisfaction. and wellness. On the contrary, if the rules of reciprocity fail, negative emotions, symptoms of stress and deterioration of health occur. According to this model, there are three types of rewards: financial, social recognition, and career opportunities or professional development. In addition, the author addresses 
the dimension of overcommitment at work, which occurs in those workers who show great effort and a strong desire for recognition, and who are at greater risk of stress because they perceive their responsibilities in an inadequate way, that is, workers underestimate the requirements and overestimate their resources or ways of dealing with them, generating situations of non-reciprocal exchanges. Previous studies have accumulated empirical evidence that supports the relationship between the imbalance between efforts and rewards and diseases associated with stress. The ERI model has represented an advance over other theoretical approaches that focus on stress, since it adds the existence of an intrinsic component that directly affects health: overcommitment. Overcommitted workers misjudge the potential harm that working conditions can cause them, and also overestimate their own abilities to cope. Specifically, the hypothesis of the model is that overcommitment moderates the effect of effort-reward imbalance on health, so that the strongest effects are expected among people with high scores in overcommitment.

Despite the empirical evidence that the ERI model has received, the mechanisms through which its negative effect on health is exerted have not yet been clarified. Several studies have explored the mediating role played by social identification in the relationship between ERI and indicators of distress [4]. Social identification has been defined as the part of the self-concept that is linked to the feeling of belonging to relevant groups. According to the Social Identity Theory, people incorporate their belonging to relevant groups in their self-concept and tend to adopt judgments, evaluations and behaviors that are encouraged or beneficial for those groups [5]. On the other hand, employees who identify more with their groups are more likely to feel like members of the endogroup and have a greater tendency to evaluate their working conditions in the same way as their colleagues [6].

Mael and Ashforth define organizational identification as a perceived unit with an organization and the experience of the successes and failures of the organization as their own. While identification is considered important to the organization, it has not been clearly put into practice. This construct reflects the bond between employees and their organization and the extent to which the employee's self-concept overlaps with their organization [7]. Research on identification has provided insights and scraps about its effect on health and well-being [8]. However, Haslam (2004) argues that "High identification does not necessarily protect employees from burnout", because highly identified employees feel compelled to work harder to achieve organizational goals \{9].

However, world events cause new forms of identification to be adopted. More specifically, Blake E. Ashforth argue that COVID-19 is encouraging people to define themselves less in terms of an "organizational we" and more like other forms of "we" alongside a personalized "me." Furthermore, these authors argue that academics would benefit from examining how event-specific organizational responses to the pandemic (and major events in general) affect identification with the organization, and how the pandemic and similar events affect identification with relevant occupations [10].

The COVID-19 pandemic has had a dramatic impact on healthcare workers around the world. This professional context has attracted the attention of many researchers [11], however, few health studies have focused on the psychosocial factors of health workers since this pandemic broke out. Health workers are occupationally exposed to psychosocial factors that can endanger their health. This research recognizes the importance of certain psychosocial factors to consider ways to prevent them, especially in this current context of pandemic. For example, how health professionals can respond to acute stress situations, when they are already affected by stressors, or how organizational identification and overcommitment on the negative effects of stress work in a context of health crisis, where the health system can be seriously damaged.

The purpose of this study was to check whether the overcommitment, included in the Theoretical Model of Effort-Reward Imbalance (ERI), moderated the relationship between the ERI and the organizational identification in a sample of Spanish health professionals. Furthermore, we also wanted to check if this effect varied depending on the professional category (doctors vs. nurses) and age. 


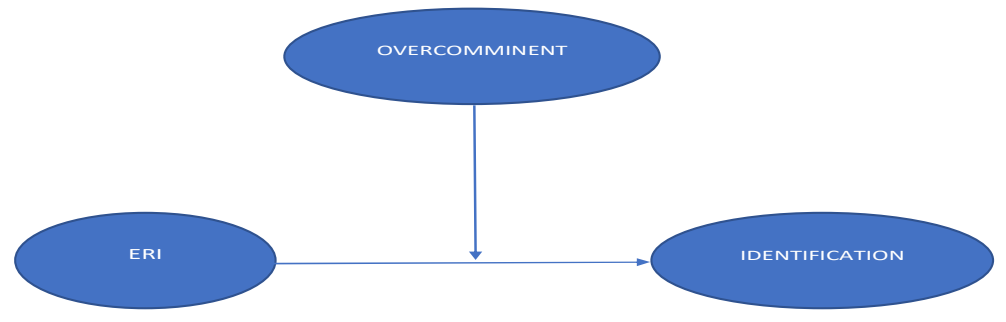

Figure 1. Moderation of the relationship between ERI and group identification.by overcommitment. Note: age is entered as a covariate

\section{Materials and Methods}

\subsection{Participants}

A sample of 623 subjects participated in the study, 164 were doctors and 459 were nursing professionals. Both samples answered a set of questions related to the imbalance between effort and received rewards (ERI), the overcommitment (intrinsic component of the ERI model), and the organizational identification. The University's Bioethics Committee approved the study design with protocol number 12201403. Recruitment was carried out through convenience sampling. The study was carried out at four hospitals in Madrid and Andalusia, reflecting a $70 \%$ response rate. The mean age of the participants was 52.88 years in the sample of doctors, and 47.25 years in the sample of nursing professionals.

\subsection{Instruments}

The questionnaire consists of a first section with demographic data and a second part with validated scales that evaluate the study variables. To measure the Effort-Reward Imbalance, the validated Spanish version of the Effort-Reward Imbalance Scale, developed by Macías Robles, Fernández-López, Hernández-Mejía, Cueto-Espinar, Rancaño, and Siegrist [12] was used, according to the Siegrist's (1996) model. This scale measures the extrinsic component and is subdivided into two subscales that measure extrinsic effort $(\alpha=.63)$ and extrinsic rewards $(\alpha=.73)$. To obtain a score that expresses the workers' perceived imbalance between effort and rewards, an overall value is calculated by subtracting the reward score from the effort. Overcommitment, included in the ERI model, was measured by the overcommitment scale $(\alpha=.75)$, validated by Macías Robles et al. [12]. Group identification was measured using the questionnaire developed by Mael and Ashforth [13], adapted for focus groups $(\alpha=.93)$.

\subsection{Data analysis}

The data were analyzed using the SPSS software package (version 24.0), with raw data as input. The descriptive statistics were calculated, along with the reliability values for all the study variables. All variables were found to have multivariate normality. Since the PROCESS macros were used to test the study hypotheses, we were able to perform a moderation analysis.

\section{Results}

The results revealed that the effect of effort-reward imbalance on organizational identification was statistically significant in professionals with medium-high overcommitment $(\beta=0.22, p<0.01 ; \beta=0.39, p<0.01)$. In the case of people with low overcommitment, this effect was not significant. These results suggest that when an imbalance between the efforts and rewards received in the organization occurred, the most overcommitment healthcare professionals identify more with the organization than those who are less committed. In addition, the relationship to age is negative and significant only for the group 
of nursing professionals $(\beta=-0.012, p<0.01)$. More specifically, older nursing professionals, were less identified with the organization. In Table 3 we summarize the main statistical results of this study.

Table 1. Main statistical results of the study.

\begin{tabular}{cc}
\hline \multicolumn{2}{c}{ NURSING PROFESSIONALS $(N=459):$} \\
\hline Negative effect of age: $\beta=-0.012, p<0.01$ & Conditional effects on different moderator values: \\
ERI: $\beta=-0.28, p=0.15$ & $1.83(\beta=0.12, p=0.09)$ \\
Overcommitment: $\beta=-0.03, p=0.75$ & $2.41(\beta=0.26, p<0.000)$ \\
& $3(\beta=0.39, p<0.000)$ \\
ERI * overcommitment interaction: $\beta=0.22, p<0.01$ & Conditional effects on different moderator values: \\
\multicolumn{2}{c}{ DOCTORS $(N=164):$} \\
\hline \multicolumn{2}{c}{$2(\beta=0.26, p=0.05)$} \\
Negative effect of age: $\beta=0.007, p=0.27)$ & $2.5(\beta=0.46, p<0.000)$ \\
ERI: $\beta=-0.53, p=0.18$ & $3(\beta=0.66, p<0.000)$ \\
ORI * overcommitment: $\beta=0.38, p<0.05$ &
\end{tabular}

\section{Discussion}

The objective of this study was to verify whether overcommitment, included in the Effort-Reward Imbalance Theoretical Model (ERI), moderated the relationship between ERI and organizational identification in a sample of Spanish health professionals. Furthermore, we also wanted to check if this effect varied according to professional category (doctors vs. nurses) and age. Likewise, it was possible to verify conditional effects in different values of the moderator (overcommitment). In light of the results, it can be concluded that when there is an imbalance between the effort and the rewards received in the organization, the most committed healthcare professionals identify more with the organization than the least committed ones. Furthermore, the relationship with age is negative and significant only for the group of nurses. In this study, older nurses identified less with the organization, so this covariate may affect differently according to the category or professional role in health professionals. Despite its limitations, this study may contribute to a better understanding of the moderating role of overcommitment and its indirect effects on organizational identification, according to chronological age and health professional role. First, the main direct effects of the ERI model are verified. Second, the indirect effect of excessive commitment is verified when workers experience situations of imbalance. Specifically, it has been suggested that overcommitment may be a predictor of ERI, rather than a simple consequence. Some authors argue that overcommitment may be an individual characteristic, with a certain degree of stability, that prompts people to compensate for the perceived imbalance by assuming a disproportionate commitment to the task they face [14]. Third, the role of identification is highlighted when the imbalance is perceived. Various studies have found that identification with the work group acts as a buffer against the demands of the work environment. Indeed, Haslam himself pointed out that shared social identity and perceived social support as a result influence the redefinition of the stressful potential value of stimuli [15].

\section{Limitations}

This study has some limitations that should be taken into account. First, the exclusive use of self-report questionnaires limits the strength of the evidence presented. Second, the sample size was not representative, so future studies should make an effort to recruit larger samples obtained using more rigorous procedures. Third, the ERI questionnaire assesses effort and rewards separately, quantifying the history of stress through an arithmetic operation; however, relationships between variables can follow non-linear patterns [16-18]. Fourth, longitudinal studies must be carried out over time, specifically, organizational events, culture and climate, can influence identification. Finally, it is convenient to investigate different sources of identification (for example, the profession). 


\section{Consclusions}

The results of this research suggest that the effects of ERI do not always follow the same direction. The present study opens an interesting field for future evidence-based interventions by suggesting that the influence of group identification can counteract the negative effects of ERI, however low and high levels of identification and overcommitment are not always positive for the well-being of professionals [19]. Consequently, interventions to cushion the negative effects of ERI should focus on managing overcommitment and identifying the group. The health of health workers in the current context of pandemic is a key task. The effects of organizational and work group identification and overcommitment suggest very promising ways of acting in the workplace.

Author Contributions: “G.T., M.LL-A., C.G-A. and G.T. contributed to the design and implementation of the research, to the analysis of the results and to the writing of the manuscript. All authors have read and agreed to the published version of the manuscript."

Funding: "This research received no external funding".

Conflicts of Interest: "The authors declare no conflict of interest."

\section{References}

1. Siegrist, J. Adverse health effects of high-effort/low-reward conditions. Journal of Occupational Health Psychology. 1996; 1(1):2741.

2. Siegrist, J.; Li, J. Associations of Extrinsic and Intrinsic Components of Work Stress with Health: A Systematic Review of Evidence on the Effort-Reward Imbalance Model. Int. J. Environ. Res. Public Health, 2016, 13, 432.

3. Siegrist J., Li J. Effort-Reward Imbalance and Occupational Health. In: Theorell T. (eds) Handbook of Socioeconomic Determinants of Occupational Health. Handbook Series in Occupational Health Sciences. Springer, Cham. 2020. https://doi.org/10.1007/978$\underline{3-030-05031-3}$ 14-1

4. Guglielmi, D., Mazzetti, G., Villano, P., \& Topa, G. The impact of perceived effort-reward imbalance on workplace bullying: also a matter of organizational identification. Psychology, Health \& Medicine. 2018; 23(5):511-516. DOI: 10.1080/13548506.2017.1363396.

5. Tajfel, H., \& Turner, J.C. The social identity theory of intergroup behavior. In S. Worchel \& W. G. Austin. (Eds.), Psychology of intergroup relations, 2nd ed. Chicago: Nelson-Hall; 1986. pp. 7-24.

6. Litchfield, R. C., Karakitapoğlu-Aygün, Z., Gumusluoglu, L., Carter, M., \& Hirst, G. When Team Identity Helps Innovation and When It Hurts: Team Identity and Its Relationship to Team and Cross-Team Innovative Behavior. Journal of Product Innovation Management. 2018; 35(3):350-366.

7. Ashforth B. Distinguished Scholar Invited Essay: Exploring Identity and Identification in Organizations: Time for Some Course Corrections. Journal of Leadership and Organizational Studies. $2016 \quad$ Nov 1;23(4):361-373. https://doi.org/10.1177/1548051816667897

8. Steffens NK, Haslam SA, Schuh SC, Jetten J, van Dick R. A Meta-Analytic Review of Social Identification and Health in Organizational Contexts. Pers Soc Psychol Rev. 2017 Nov;21(4):303-335. doi: 10.1177/1088868316656701. Epub 2016 Jul 7. PMID: 27388779.

9. Haslam, S. A. (2004). Psychology in organizations: The social identity approach (2nd ed.). London: Sage.

10. Ashforth, B.E. Identity and Identification During and After the Pandemic: How Might COVID-19 Change the Research Questions we Ask?. J. Manage. Stud. 2020, 57: 1763-1766. https://doi.org/10.1111/joms.12629

11. Chirico, F., Nucera, G., \& Magnavita, N. (2020). COVID-19: Protecting Healthcare Workers is a priority. Infection Control \& Hospital Epidemiology, 41(9), 1117-1117. doi:10.1017/ice.2020.148.

12. Macías Robles, M.D., Fernández-López, J.A., Hernández-Mejía, R., Cueto-Espinar, A., Rancaño, I. \& Siegrist, J. Evaluación del estrés laboral en trabajadores de un hospital público español. Estudio de las propiedades psicométricas de la versión española del modelo Desequilibrio Esfuerzo-Recompensa. Medicina Clínica. 2003; 120 (17):652-7.

13. Mael F, Ashforth BE. Alumni and their alma mater: A partial test of the reformulated model of organizational identification. Journal of Organizational Behavior. 1992 Mar;13(2):103-123. https://doi.org/10.1002/job.4030130202.

14. Feldt T, Hyvönen K, Mäkikangas A, et al. Overcommitment as a predictor of effort-reward imbalance: evidence from an 8-year follow-up study. Scandinavian Journal of Work, Environment \& Health. 2016 Jul;42(4):309-319. DOI: 10.5271/sjweh.3575.

15. Haslam, S. A., Jetten, J., O'Brien, A. \& Jacobs, E. Social identity, social influence and reactions to potentially stressful tasks: support for the self-categorization model of stress. Stress and Health. 2004; 20 (1): 3-9.

16. Cuitún Coronado, J., Chandola, T., \& Steptoe, A. Allostatic load and effort-reward imbalance: Associations over the workingcareer. International Journal of Environmental Research and Public Health. 2018; 15(2): 191.

17. Knudsen, A. K., Harvey, S. B., Mykletun, A., \& Øverland, S. Common mental disorders and long-term sickness absence in a general working population. The Hordaland Health Study. Acta Psychiatrica Scandinavica. 2013; 127(4): $287-297$. 
18. Stadin, M., Nordin, M., Broström, A., Hanson, L. L. M., Westerlund, H., \& Fransson, E. I. Information and communication technology demands at work: the association with job strain, effort-reward imbalance and self-rated health in different socio-economic strata. International Archives of Occupational and Environmental Health. 2016; 89(7): 1049-1058.

19. Avanzi, L., Savadori, L., Fraccaroli, F. et al. Too-much-of-a-good-thing? The curvilinear relation between identification, overcommitment, and employee well-being. Curr Psychol (2020). https://doi.org/10.1007/s12144-020-00655-x 